\title{
HOMENAJE AL PROFESOR JORGE AYALA
}

\author{
Homage to Professor Jorge Ayala \\ Joaquín Lomba Fuentes \\ Universidad de Zaragoza
}

\section{RESUMEN}

Este escrito es un homenaje al Prof. Jorge Ayala Martínez por sus muchos méritos contraídos a lo largo de su vida, como docente en distintos centros, sobre todo en la Universidad de Zaragoza y como investigador. Su especialidad es la Filosofía, especialmente española, aragonesa y medieval, además de otros campos. Por otro lado, su labor como Secretario de la Sociedad de Filosofía Medieval (SOFIME) y como Director de esta revista, ha sido sumamente loable y eficaz.

Palabras clave: Filosofía medieval, Filosofía española y aragonesa, Baltasar Gracián, Filosofía de la religión.

\begin{abstract}
This writing is an homage to Professor Jorge Ayala Martínez because of his many merits in the course of his life as a teacher in different centers, especially in the University of Zaragoza, and as an investigator. His speciality is Philosophy, above all the Spanish, Aragonese and Medieval Philosophy, and other matters. On the other hand his work as a secretary and editor of this magazine Medieval Philosophy Society (SOFIME) has been very praiseworthy and effective.
\end{abstract}

Key words: Medieval Philosophy, Spanish and Aragonese Philosophy, Baltasar Gracián, Philosophy of Religion.

Es para mi un honor, un deber y una alegría escribir estas líneas dedicadas de todo corazón al Profesor, compañero y amigo Jorge Ayala Martínez. Hace treinta y tres años que le conozco y hemos tenido tareas comunes de las que tengo un magnífico recuerdo a través de las cuales, además, me ha dado muestras de su gran valía, su honestidad, su enorme espíritu de trabajo, compañerismo y humanidad. Por otro lado, con esta ocasión, merece la pena desgranar, aunque sea brevemente, su riquísimo curriculum, desconocido para muchos, lo cual es fruto de su enorme labor, tenaz, entregada y callada. Callada, porque Jorge Ayala no ha exhibido jamás sus trabajos ni ha hecho gala de sus méritos. Incluso para mí, que lo he tratado muy de cerca, a la hora de hacer este elogio suyo, me he encontrado con la gran sorpresa de su enorme y extensa labor. Sea este un mérito indudable, nada común hoy día. Trataré de hacer un resumen de su rica personalidad y vida.

Jorge Ayala nació en Corella (Navarra) el 28 de Julio de 1938. Tras su ingreso en la Congregación religiosa de los Claretianos, cursó sus primeros estudios eclesiásticos a los dieciocho años, en 1956, en Solsona (Lérida), continuándolos desde 1960 hasta 1964 en la Universidad de Salamanca. En este último año, 1964, se ordenó sacerdote en el mismo Salamanca. A continuación, de 1964 a 1966, obtuvo una diplomatura en la Escuela Vaticana de Paleografía y Diplomática, pasando inmediatamente a licenciarse en Filosofía durante el año 1967-1968 en el Instituto de Filosofía «Santo Tomás de Aquino» de Roma. Luego consiguió el mismo título 
estatal en la Universidad de Valencia en 1971, en la que leyó su tesis doctoral en 1973 con el título Fenomenología de la religión, que fue calificada con sobresaliente cum laude, de cuyo tema hablaré más adelante.

A continuación, inició su carrera docente al ser nombrado en 1975 Profesor Interino de Filosofía en el Departamento de Filosofía de la Universidad de Zaragoza, entonces dirigido por el gran y admirado maestro (y amigo mío) el Catedrático Dr. D. Eugenio Frutos Cortés. En 1984 pasó a ser Profesor Titular del mismo Departamento, hasta el año 2008 en que se jubiló. Las asignaturas que impartió fueron: »Filosofía», «Historia de la filosofía medieval», además de «Derechos humanos» y «Ética». En todo este tiempo en que fue profesor en la Universidad de Zaragoza tuvo una ejemplar entrega a su labor docente, preparando meticulosamente sus clases y estando siempre pendiente de los alumnos a los que recibía con suma amabilidad en su despacho.

Además de esta labor docente en el Departamento de Filosofía de la Universidad de Zaragoza, hay que añadir los diez años en que fue Profesor Tutor del Centro Asociado de la UNED de Calatayud haciéndose cargo de las asignaturas de «Historia de la Filosofía» y de «Filosofía de la educación», todo lo cual, como siempre, llevó a cabo con excelente dedicación y resultados. También fue profesor de la Facultad de Ciencias de la Educación y en la Escuela Universitaria de Estudios Sociales de Zaragoza.

Por otro lado, fue profesor también del CRETA (Centro Regional de Estudios Teológicos de Aragón) desde 1972 hasta 2009 en que se jubiló, impartiendo las asignaturas de «Antropología filosófica» y de «Filosofía de la naturaleza». Precisamente, en dicho Centro pronunció la lección inaugural del curso 1979-1980 con el título Reflejo y reflexión: B. Gracián, un estilo de filosofar (tema que, como veremos, fue uno de sus preferidos), y el 28 de Septiembre de 2009 se le rindió un merecido homenaje con motivo de su jubilación en la apertura de curso del 2009-2010, presidida por el Arzobispo de Zaragoza, Dr. Manuel Ureña.

Y volviendo a su trabajo, dentro del Departamento de Filosofía de la Universidad de Zaragoza, quiero indicar que, tras la breve estancia en Zaragoza del Prof. Ramón Valls como catedrático de Filosofía, ocupé yo mismo dicha cátedra por traslado desde Murcia, en 1979. En este Departamento me encontré con un pequeño grupo de magníficos profesores, amigos y compañeros, entre los que se encontraba Jorge Ayala, al que nombré Secretario del Departamento, cargo que desempeñó admirablemente y con toda pulcritud hasta 1997 en que cesé como Director del Departamento y él también como Secretario.

Aparte de esta larga trayectoria docente a la que se ha entregado siempre en cuerpo y alma, ha trabajado como investigador de una manera infatigable, tenaz y honesta a la vez que callada, como dije antes y quiero repetirlo por ser esta una característica de su personalidad. Apretado currículum que, no completo, abarca más de cuarenta folios. Dados los límites marcados por esta revista, me veo obligado a hacer un rápido resumen del mismmo. Un resumen que dará cuenta de la amplísima labor que Jorge Ayala ha desarrollado.

Así, hay que empezar diciendo que su interés intelectual se centró sobre todo, pero no en exclusiva, como veremos, en la filosofía, sintiendo una especial atracción por el pensamiento medieval, dando preferencia al español y al desarrollado en Aragón, sin excluir, de ningún modo, tal como veremos, el de otros campos, como es el Humanismo, el Barroco, la Ilustración, el Krausismo y el pensamiento desarrollado en el siglo XX, aparte de la dimension religiosa, como expondré más adelante.

Todo ello se plasma en sus numerosas publicaciones hechas desde 1978 hasta la actualidad entre las que se encuentran cuatro valiosos libros a los que luego aludiré, mas otros cuarenta en que participó o figura como coordinador, además de los más de cien artículos de revista publicados no solo en España sino en otros países como Chile, Francia, Portugal, 
Canadá, Argentina y otros, los cuales han merecido la recensión y comentarios de revistas tan prestigiosas como Cuadernos Salmantinos de Filosofía, Bulletin de Philosophie Médiéval de Lovaina, The Philosophical Index, Repertoire Bibliographique de la Philosophie, Revista de Hispanismo Filosófico, Diálogo Filosófico, etc. A todo lo cual hay que añadir los numerosos congresos de filosofía a los que ha asistido por invitación de los mismos, con treinta y ocho ponencias, veinticuatro comunicaciones y veintisiete conferencias. Congresos, por cierto, celebrados en Salamanca, Zaragoza, Calatayud, Córdoba, Madrid, Vic, Huesca, Toulouse, Palermo, Spoletto, Nápoles, Brighton, Ottawa, Porto Alegre, Moscú, Estambul y Seúl..

De este modo, yendo a la temática de todos estos valiosos trabajos, el autor que más ha atraído su atención ha sido el bilbilitano Baltasar Gracián al que dedicó una muy valiosa e importante monografía en 1987, Baltasar Gracián, Vida, estilo y reflexión que ha pasado a ser uno de los mejores estudios sobre este autor, al cual hay que añadir más de veinte artículos de revista y la asistencia, además, a otra veintena de Congresos ocho de ellos como ponente y numerosas conferencias, llegando a ser así Jorge Ayala uno de los mejores especialistas entre los gracianistas de todo el mundo, testigo de lo cual son las muchas recensiones que se han hecho este libro y sus trabajos dentro y fuera de España.

Y siguiendo con los diversos temas y autores que ha trabajado, dentro del horizonte expuesto y que centraron la atención de Jorge Ayala, hay que destacar cuatro importantes libros más: uno, sobre el muniesino Miguel de Molinos en 2000, sencillamente titulado Miguel de Molinos. Otro importante libro es el dedicado al navarro Juan David García Bacca en 2005, titulado J. D. García Bacca. Biografía intelectual (1912-1938), el cual tuvo una gran repercusión en los medios intelectuales. Y, finalmente una muy extensa obra consagrada al pensamiento en Aragón, en 2001, titulada Pensadores Aragoneses. Historia de las ideas filosóficas en Aragón. Esta obra es una de las más importantes que hay para conocer las ideas y el pensamiento en Aragón. Todos estos libros han recibido, como todo el resto de su producción intelectual, los más encomiados elogios en numerosas revistas de dentro y fuera de España.

También ha trabajado y publicado numerosos estudios, de los cuales solo citaré algunos pocos, los más significativos y que muestran el amplio abanico de sus intereses. Así, se encuentran los siguientes artículos de revista ordenados cronológicamente: Francisco Quevedo, genio verbal y pensador de la vida (1981), Filosofía e Historia en Eugenio D'Ors (1983), Ortega y Gasset y las ideas darvinistas (1982), El Ingenio en Huarte de San Juan y otros escritores españoles (1990), El Maestro darocense Pedro Sánchez Ciruelo (1993), Miguel de Unamuno, sembrador de inquietudes religiosas (1995), Juan Luis Vives y la crítica de los humanistas a la lógica escolástica (1996), Un centenario a debate. ¿Qué ha aportado a la Filosofía Española a la celebración del primer centenario del nacimiento de Ortega y Gasset? (1996), Filósofos aragoneses de nuestro siglo: Miguel Asín Palacios (1997), Descargo de conciencia dedicado a Pedro Laín Entralgo (1998), Ramón J. Sender: raíz antropológicomoral de su obra literaria (1998), José Camón Aznar, Jesucristo. Reflexiones sobre los relatos evangélicos (1998), El regeneracionismo científico de Ramón y Cajal (1999), Krausismo y renovación escolástica en Aragón (2000), Humanismo filosófico de Andrés Piquer (2006).

Igualmente se ha asomado al mundo judío y musulmán medievales, escribiendo «Guía de perplejos» de Maimónides. (1985), El Racionalismo ético de Salomon Ibn Gabirol (1995), ¿Fue Averroes un averroísta? (1997), La Ética de Maimónides (2004), además de cuatro artículos sobre pensamiento medieval en general, mas nueve sobre el mismo tema ciñéndose a Aragón.

Acabamos de ver el amplio y rico horizonte de intereses que tuvo dentro de la filosofía. Pero falta un aspecto muy importante en su vida que conecta con sus primeros estudios, su tesis doctoral en Valencia y su condición de sacerdote, pues por encima y antes que profesor e

Revista Española de Filosofía Medieval, 19 (2012), ISNN: 1133-0902, pp. 53-57 
investigador se encontraba, esta dimensión que fue, sin duda, el alma impulsora de todo. Así, como sacerdote, me consta la gran estima que ha merecido de sus compañeros y superiores de su orden religiosa y de quienes acudieron a él como sacerdote. De hecho, le han confiado varias veces tareas de gobierno dentro de su congregación. Por otro lado, su dimensión religiosa, se manifiesta abundantemente, como veremos, en sus mismas investigaciones.

En efecto, aparte de su extensa producción en filosofía, publicó diez artículos sobre temas religiosos, desde 1994 hasta 2001 abordándolos desde distintos puntos de vista. Es interesante ver algunos de los aspectos que más le han interesado. En primer lugar, su tesis doctoral leída en la Universidad de Valencia titulada, como hemos visto, Fenomenología de la religión y un artículo publicado en 1995 con el mismo título, resumiendo su pensamiento sobre el hecho religioso. Son sus mismas palabras las que sintetizan su pensamiento: «El hecho religioso pertenece a la experiencia humana, y como tal puede ser estudiado en todas las culturas, desvelando sus particularidades y características universales. La estructura significativa del fenómeno religioso es diferente del que presentan otros fenómenos intencionales próximos a él: éticos, políticos, sociales. Dicha estructura significativa recibe primeramente el nombre de Sagrado; después el nombre de Misterio, que simboliza la superioridad de ese Otro que se hace presente en la vida de la persona. Finalmente se aplica el nombre de Dios a la personalización de la Divinidad». Otro aspecto que le interesa es el del futuro de las religiones sobre el que ha publicado tres trabajos: El futuro de las religiones (1995), El mañana del fenómeno religioso. (1996) y Conflicto, diálogo y futuro de la religión en España (1997). Igualmente son sus mismas palabras las que resumen su pensamiento: «Nuestra época se caracteriza, en lo religioso, por una especie de eclipse de Dios, pero también se advierte un progresivo retorno religioso o reencantamiento del mundo. La llamada crisis religiosa es interpretada por algunos como liquidación de la religión. Pensamos, por el contrario, que la conciencia de crisis es conciencia de cambio. El futuro de las religiones depende en gran medida de cómo vayamos asumiendo los cambios y dando respuesta a los mismos desde nuestras respectivas religiones».

Finalmente, el tema religioso le sale al encuentro con frecuencia a Jorge Ayala bajo otros puntos de vista, como indican algunos de los trabajos que ha publicado: El arte mudéjar, un arte de convivencia típicamente español. (1994), Identidad y pluralismo en el diálogo interreligioso (1999), Religión y Cultura: la enculturación de la religión (2000) y otros más. Baste con lo dicho para conocer esta otra faceta de Jorge Ayala.

Para terminar, quiero hacer referencia a un tema que, aparte de la relación que tuvimos Jorge Ayala y yo en el Departamento de Filosofía, nos implica dilectamente también y del que soy testigo muy directo de su excepcional entrega y dedicación al trabajo e indudable eficacia y honestidad. Es además un tema que atañe muy directamente a esta revista en que escribo el presente homenaje. Me refiero a la Sociedad de Filosofía Medieval (SOFIME) y a la Revista Española de Filosofía Medieval.

Fue a finales de 1989 cuando planteé a Jorge Ayala la posibilidad de fundar dicha Sociedad. A los dos nos pareció esta idea de lo más oportuna y necesaria y nos pusimos con toda ilusión manos a la obra. Tras numerosas reuniones entre Jorge Ayala y yo, diseñamos lo que podía ser dicha Sociedad. Cuando estuvimos decididos a acometer la empresa, invitamos a colaborar en el proyecto a los dos medievalistas que había entonces en la Universidad de Zaragoza: el Prof. Antonio Ubieto, desagraciadamente fallecido, y la Profra. María Jesús Lacarra. Y no tardamos mucho en ponernos en contracto con los mejores especialistas en pensamiento medieval españoles de casi todas las Universidades españolas y del Consejo Superior de Investigaciones Científicas. Sin la colaboración entusiasta de todos ellos hubiera sido imposible el que esta Sociedad naciese y funcionase hasta hoy. Pero hay que subrayar también que sin la entrega y eficaz trabajo, día a día, de Jorge Ayala, como Secretario de la Sociedad, tampoco hubiera sido posible. Y de ello soy testigo muy directo desde 1989 hasta hoy.

Revista Española de Filosofía Medieval, 19 (2012), ISNN: 1133-0902, pp. 53-57 
De este modo, se constituyó la Sociedad, con noventa miembros procedentes no solo de España sino también de Francia, América Latina, Marruecos y otros países, cifra que ha ido creciendo hasta la actualidad en que sobrepasa el doble de los socios, algunos de ellos, como en sus inicios, de fuera de España. Así, se decidió celebrar un primer Congreso en Zaragoza y luego, los siguientes, cada cuatro años. Este primer Congreso de Zaragoza tuvo lugar en 1990, con la asistencia de ciento ochenta congresistas, algunos de ellos procedentes de Francia, Argentina, Marruecos. Dicho congreso fue patrocinado por IberCaja al igual que los dos siguientes, la cual, además, nos cedió sus locales para la celebración del Congreso y las reuniones de la Junta Directiva. En este Congreso se aprobaron los Estatutos, se formó oficialmente la Junta Directiva (integrada por medievalistas españoles de máximo prestigio) y se procedió a los trámites administrativos en orden a la constitución oficial de la Sociedad. En 1991 se adscribió la Sociedad al Departamento de Filosofía de la Universidad de Zaragoza del que Jorge Ayala, como he indicado antes, era Secretario. Hay que subrayar la entusiasta acogida que dicho Departamento mostró a esta iniciativa, apoyando en todo momento a la Sociedad. Y volviendo a este primer congreso, fue Jorge Ayala el encargado de coordinar y realizar las Actas, que salieron publicadas en 1992. Coordinación que también llevó a cabo Jorge Ayala en las Actas del Segundo y tercer Congreso, publicadas respectivamente en 1996 y 1999.

Otra de las decisiones que tomó la Sociedad fue la Sociedad fue la de editar anualmente una publicación que tomó el nombre de Revista Española de Filosofía Medieval en la que escribo este homenaje. La revista, al igual que la Sociedad, la asumió con todo interés el Departamento de Filosofía de Zaragoza. El primer número, el 0, vio la luz en 1993. Y hay que subrayar también, que aunque figuraba yo como Director de la misma, en realidad, el que la llevó adelante por completo fue Jorge Ayala, como secretario de la misma, el cual pasó a ser Director en 2004. Muchos han colaborado en su realización como los sucesivos subdirectores (actualmente el Prof. Eudaldo Forment) y Secretarios (ahora el Prof. Pedro Mantas). Pero el esfuerzo, dedicación absoluta en la elaboración de cada número, hasta en los más mínimos detalles de Jorge Ayala ha posibilitado la realización práctica de la misma, habiendo conseguido estar entre las primeras en los ranking, tanto españoles como extranjeros, sobre publicaciones periódicas de filosofía. En efecto, cada número desde el número 0 hasta el presente, 19 , ha sido él quien la ha llevado adelante en todos sus más mínimos detalles. Más aún, personalmente le debo el que haya llevado a cabo con gran entusiasmo, el número 10, titulado Miscelánea Medievalia, en honor de Joaquín Lomba Fuentes, lo cual le agradezco profundamente.

Esta es la semblanza, muy abreviada, de un hombre totalmente entregado a sus grandes vocaciones personales, docentes, académicas, intelectuales e investigadoras, además de sus tareas como gestor en la Universidad, en el CRETA, en la Sociedad de Filosofía Medieval y en esta Revista Española de Filosofía Medieval. Y ello, de una manera totalmente eficaz, pero en silencio, callado como he repetido varias veces en esta semblanza. Sin duda que merece un homenaje mucho más amplio que el que le ofrezco. Pero valgan estas modestas líneas que le dedico de todo corazón y con mi admiración, en nombre de tantos y tantos amigos, compañeros, alumnos que lo hemos conocido.

Para terminar, bien se puede aplicar al Prof. Jorge Ayala lo que dijo un sabio persa del s. XI: «Quien sabe, obra bien y enseña, merece ser llamado Grande».

Joaquín Lomba Fuentes jlomba@unizar.es

Encargado: 15 de enero de 2011

Aceptado: 1 de marzo de 2012

Revista Española de Filosofía Medieval, 19 (2012), ISNN: 1133-0902, pp. 53-57 